\title{
Evaluación diagnóstica a nuevos estudiantes de carreras pedagógicas en Universidades Chilenas del Estado: representaciones sociales sobre el ejercicio profesional docente
}

\section{Diagnostic Assessment for Students who Enroll in Pedagogical Programs in Chilean State Universities: Social Representations about Teaching Professional Performance}

\author{
Alex Pavié-Nova* \\ Universidad de Los Lagos, Chile \\ ORCID: http://orcid.org/0000-0002-9614-4206 \\ Pedro Sandoval-Rubilar \\ Universidad del Bío-Bío, Chile \\ ORCID: http://orcid.org/0000-0001-7503-756X \\ Claudia Rubio-Benítez \\ Universidad de Los Lagos, Chile \\ ORCID: https://orcid.org/0000-0002-8507-7677 \\ Ana C. Maldonado \\ Universidad del Bío-Bío, Chile \\ ORCID: http://orcid.org/0000-0002-9198-5882 \\ Víctor H. Robles-Francia \\ Universidad Juárez Autónoma de Tabasco, México \\ ORCID: https://orcid.org/0000-0003-1046-4768
}

Recibido 02-01-20 Revisado 15-02-20 Aprobado 30-03-20 En línea 07-04-20

*Correspondencia

Email: apavie@ulagos.cl
Citar como:

Pavié-Nova, A., Sandoval-Rubilar, P., Rubio-Benítez, C., Maldonado, A. C., \& Robles-Francia, V. H. (2020) Evaluación diagnóstica a nuevos estudiantes de carreras pedagógicas en Universidades Chilenas del Estado: representaciones sociales sobre el ejercicio profesional docente. Propósitos y Representaciones, 8(SPE1), e493. doi: http://dx.doi.org/10.20511/pyr2020.v8nSPE1.493 


\section{Resumen}

Este estudio es de tipo descriptivo e interpretativo y da cuenta de los resultados de las representaciones sobre la profesión docente - con énfasis en el ejercicio profesional docente - que auto-reportan alumnos que ingresan a la Formación Inicial de profesores, en siete instituciones chilenas de Educación Superior estatales. Este estudio surge a partir de la actualización del sistema nacional de aseguramiento de la calidad de la educación, en donde se establece la obligatoriedad de aplicar test de evaluación diagnóstica. Para tal efecto la población estudio estuvo conformada por 1836 estudiantes de la cohorte 2019, pertenecientes a carreras de Pedagogía de estas Universidades del país. Se aplicó un instrumento escala tipo Likert. Para realizar el análisis de la información se aplicaron métodos descriptivos numéricos e inferenciales. En sus principales conclusiones, se devela representaciones comunes en dimensiones sobre ejercicio profesional docente, independiente del sexo, de lo que se desprende que los sujetos evaluados conforman una identidad profesional claramente modelada antes de comenzar su Formación Inicial Docente.

Palabras clave: Evaluación Nacional Diagnóstica; Representaciones sociales; Ejercicio profesional docente.

\section{Summary}

This descriptive and interpretative study accounts for results of representations regarding teaching profession which students of initial teaching training report in seven state chilean Higher Education institutions. This study arises from the updating of the national education quality assurance system in which the obligation to apply a diagnostic test is established. For such a purpose, the study population was composed by 1836 students from 2019 cohort of pedagogical programs from this national universities. A Likert - like scale instrument was applied. Numerical descriptive and inferential methods were applied to analyze the information. Generally concluding, common representations are revealed a professional performance regardless of the sex; it suggests that the evaluated subjects shape a clearly modeled professional identity before starting their Initial Teaching Training.

Keywords: Diagnostic National Assessment; Social Representations about Teaching Profession; Teaching Professional Performance.

\section{Introducción}

La relación establecida entre calidad de la educación y calidad de la docencia ha sido fundamentada ampliamente por la literatura especializada en los últimos 25 años, autores como Contreras (1985), Barber y Mourshed (2008), Vaillant (2014), Hirmas (2014), Marcelo (2016), Ruffinelli (2017), Medina (2018) y Cabezas et al. (2019), por nombrar a algunos de ellos. Atendiendo a ello, se gestaron en América Latina numerosas políticas de estabilidad laboral, capacitación y perfeccionamiento de los profesores en servicio (Sandoval, 2009). Chile también formó parte activa en las propuestas para mejorar la calidad de la educación centradas en la calidad del desempeño docente. Algunas acciones realizadas vinculadas al profesorado, fueron la creación de la Ley de Estatuto Docente, la asignación de premios de excelencia y estímulos al perfeccionamiento dentro y fuera del país (Sandoval, 2009).

Así, en la década del '90, organizaciones internacionales como el Banco Mundial, Organización para la Cooperación y el desarrollo económico (OCDE), Organización de las Naciones Unidas para la Educacion, la Ciencia y la Cultura (UNESCO), entre otras, introducen el concepto de calidad como eje orientador de las políticas educativas del continente (Reimers, 2000). La calidad, más la equidad y la eficiencia, constituyeron el marco orientador de todas las reformas educacionales. De esta suerte, el estudio de los factores que la favorecen guió el debate, 
fundamentalmente, hacia la revisión de los procesos educativos y las competencias profesionales de los educadores (Álvarez \& Ruiz Casares, 1997; Pavié, 2011). Hoy existe un consenso generalizado de que en todos los factores internos en los centros educativos que afectan el aprendizaje y el rendimiento escolar, el más relevante es el del profesor, no en cuanto evaluaciones, niveles, recursos o liderazgo escolar, sino la calidad del docente (Hargreaves \& Fullan, 2014; CNA, 2018).

Pese a los evidentes progresos en el área, la calidad y equidad en educación, en gran parte del continente, "siguen siendo propósitos y todavía no constituyen plenamente una solución, dado que los esfuerzos realizados no han servido del todo, para garantizar un desarrollo educativo sostenido" (Vaillant, 2005). La evidencia que sostiene lo anterior, es el reposicionamiento de la discusión sobre calidad que se impone con énfasis en la agenda gubernamental chilena, posterior a los movimientos estudiantiles de los años 2006 y 2011, respectivamente. Las resistencias originadas por las movilizaciones, obligaron discutir las concepciones que constituyen la educación desde lo político, económico y lo educativo, poniendo en duda el concepto de calidad que se venía construyendo hasta el momento (Sánchez, 2013). En este contexto, se abordaron diversos aspectos como, por ejemplo, la creación de organismos fiscalizadores; la evaluación del sistema de gestión de las escuelas y en especial, el seguimiento a la docencia, situando al profesorado una vez más, al centro de la discusión.

En la última década, la preocupación del Estado de Chile en asuntos referente a la docencia se concreta en dos líneas de acciones: (I) monitoreo de la idoneidad de los docentes en ejercicio; y (II) pertinencia de las trayectorias de formación docente. Al interior de la primera línea de acciones, a la Evaluación Docente implementada en el año 2005, se sumó la promulgación de la Nueva Carrera Docente en el año 2016, que enfatiza en la profesionalización de los profesores en ejercicio. La ley surge de la sentida necesidad de valorar la docencia y el carácter estratégico de dicha profesión, a través de políticas que favorezcan las condiciones laborales y de desarrollo profesional acordes a la envergadura de la tarea (Ruffinelli, 2017).

Dentro de las acciones intencionadas a mejorar los procesos formativos de los futuros profesores, una de las tareas en proceso de implementación es la Evaluación Nacional Diagnóstica (END), prescrita en la revisión de la ley sobre Sistema Nacional de Aseguramiento de la Calidad de la Educación (Ministerio de Educación de Chile -MINEDUC-, 2006. Actualizada 29 de mayo 2018). En esta se espera que las instituciones formadoras de docentes implementen evaluaciones al comienzo y al término de la trayectoria formativa, con el propósito de recoger información para mejorar tanto los procesos formativos como el currículum. En complemento con lo anterior, tiene que existir una política pública unificada e integrada, que entregue líneas de referencia claras con respecto a la FID con el propósito a mediano plazo de diseñar programas de formación que guarden coherencia con estas líneas y que consideren las asignaturas pertinentes para esta implementación (Medina, 2018; Cabezas et al., 2019).

Se considera oportuno considerar que en el caso de las pedagogías, la Formación Inicial Docente (FID) logra erradicar solo de manera parcial las representaciones y creencias que los profesores en formación construyen en sus doce años de escolaridad previa y obligatoria. Siempre que las prácticas y conductas se cimientan en las representaciones y creencias que les otorgan sentido (Banchs, 1986), el paso por la universidad aparece como un periodo demasiado breve para reconstruir o re-significar tales representaciones; las que están basadas en experiencias escolares anteriores.

La literatura especializada demuestra propone que existe una tendencia en los profesores a desempeñarse con prácticas de enseñanza muy similares a aquellas con las que ellos aprendieron y/o fueron formados, y que están en directa relación con la noción de ser profesor que han desarrollado a lo largo de su vida (Pozo, 2009 y 2014; Russell, 2014). La experiencia de la escuela tiene una marcada huella en las representaciones con que ingresan los nuevos estudiantes a las carreras de pedagogía y han demostrado ser persistentes en el tiempo pese a los esfuerzos en los 
procesos formativos universitarios. En consecuencia, se determina que el proceso de transformarse en profesor comienza antes del ingreso a la FID, en una etapa anterior a la universidad, en donde se experimentan una serie de vivencias que demarcan la idea acerca de lo que significa ser profesor (Britzman, 2003; Caine \& Steeves, 2009; CNA. 2018).

No obstante, los individuos también son agentes activos de sus creencias y representaciones. Lo anterior, al implicar su pensamiento en procesos epistemológicos que les facilita dejar de reproducir su entorno social simbólico de manera mecánica y habitual, se desempeñan sobre su realidad, redefiniendo tales representaciones. De acuerdo a lo anterior, en el contexto chileno interesa indagar en las representaciones con que nuevos estudiantes ingresan a las carreras de pedagogía, superando el trámite que muchas veces significan las pruebas estandarizadas en las que las políticas nacionales han puesto especial atención. Así, identificar las representaciones de los estudiantes nos otorga la posibilidad de anticipar determinadas prácticas docentes, así como también ajustar las trayectorias formativas generando los espacios para reconstruir, reflexionar, y re-conceptualizar las creencias implícitas de los profesores en formación. Este texto propone avanzar en ese trazado, indagando en las representaciones acerca de la docencia, valoraciones y opiniones relacionadas con su profesión al momento de ingresar a estudiar alguna pedagogía. Especial atención se le entrega a la idea de ejercicio profesional docente, como elemento determinante en la elección de una carrera pedagógica y la permanencia en el ejercicio docente propiamente dicho (Ávalos, 2014; Ruffinelli, 2017).

De acuerdo a lo anterior, el objetivo principal de este artículo es identificar, describir y comparar las representaciones sobre la profesión docente, que han elaborado los estudiantes que ingresan a estudiar carreras de Pedagogías, específicamente en el contexto del ejercicio profesional docente de siete universidades regionales estatales del país.

\section{Marco referencial sobre representaciones de la profesión docente}

En el campo de la sociología la discusión referente a la relación entre lo colectivo y lo individual, como diálogo y disputa de los campos simbólicos a los que refiere el pensamiento, se inicia con los postulados de Durkheim $(1895,1987)$ que incorporan la interacción social como determinante de las experiencias del sujeto y su comprensión del mundo. El contexto social, para el autor, está expuesto a procesos de interpretación colectivos que construyen representaciones que determinan a los sujetos y a su forma de concebir esos contextos.

Basados en los postulados de Durkheim, Berger y Luckmann definieron la sociedad como un producto humano, que en la intersubjetividad se convierte en una realidad objetiva, con estructuras y límites definidos. Estas estructuras determinan la subjetividad y la forma en que los sujetos se desenvuelven en ella: "la sociedad es una realidad objetiva, el hombre es un producto social" (Berger \& Luckmann, 1993, p.61). Si bien el concepto de Representaciones Sociales (RS) fue acuñado por Moscovici en 1962, para referirse al pensamiento social desde una perspectiva constructivista, fue posterior a las lecturas de Berger y Luckmann que desarrolló la idea de RS, como "un corpus organizado de conocimientos y una de las actividades psíquicas gracias a las cuales los hombres hacen inteligible la realidad física y social, se integran en un grupo o en una relación cotidiana de intercambios, liberan los poderes de su imaginación” (Moscovici, 1979, p.18). El interés investigativo del autor, fue la construcción social de la realidad y cómo las personas construyen y son construidas al interior del sentido común (Araya, 2002, p.13). Le asigna al sentido común la categoría de pensamiento social, con estructuras y jerarquías cualitativamente equiparable a cualquier otra forma de conocimiento, (Moscovici, 1998; Abric, 2001).

Jodelet complementa los postulados de Moscovici, abordando el sentido común como conocimiento espontáneo, habitualmente concebido en oposición al pensamiento científico, pero con la capacidad de estructurar prácticas y experiencias cotidianas de los sujetos: "este 
conocimiento se constituye a partir de nuestras experiencias, pero también de las informaciones, conocimientos y modelos de pensamiento que recibimos y transmitimos a través de la tradición, la educación y la comunicación social. De este modo, ese conocimiento es en muchos aspectos un conocimiento socialmente elaborado y compartido" (Jodelet, 1986, p.473).

$\mathrm{Al}$ interior de las RS distingue tres dimensiones: (I) actitud, (II) información y (III) campo de representación (Moscovici, 1979). (I) La actitud, refiere a la orientación positiva o negativa de una representación. Corresponde a la dimensión afectiva que clasifica la realidad material y social de forma simbólica, favorable o desfavorablemente (Mora, 2002); (II) La información refiere a la cantidad y organización de los conocimientos de una persona o grupo social sobre un objeto o situación determinada. Esta dimensión reconoce la clasificación de determinados conceptos en prejuicios o estereotipos vinculados a la dimensión actitudinal anterior (Araya, 2002); (3) El campo de representación constituye la estructura jerárquica que organiza actitudes e información. Incluye el conjunto de opiniones, imágenes, creencias, vivencias y valores presentes en una misma representación social, organizados en un esquema figurativo construido en el proceso de objetivación. Este esquema le confiere significado a los demás elementos presentes en el campo de la representación (Araya, 2002, p.41).

Explorar las representaciones sociales tiene un sentido práctico, concurrente a la construcción de una realidad común de un conjunto social (Jodelet, 1986). Implica el acceso a una galería mental de representaciones jerarquizadas y estructuradas que corresponde a un determinado grupo de pertenencia (Domínguez, 2001). En el área de la educación, las representaciones sociales tienen especial relevancia en tanto favorecen y reproducen un determinado modelo docente, construido sobre experiencias e interacciones de los sujetos en sus trayectorias escolares y vivencias cotidianas, permitiendo anticipar su desempeño profesional (Kaplan, 1997). En otras palabras, los programas FID tienen una responsabilidad gravitante al ser el primer paso que luego da acceso al desarrollo profesional docente (Vaillant, 2014).

En coherencia con lo anterior, este trabajo pretende acceder a las representaciones sociales acerca de la profesión docente, de los sujetos que ingresan a estudiar pedagogía, construidas al interior de lo que habitualmente denominamos sentido común. Explora en la dimensión actitud, para reconstruir disposiciones y valoraciones conferidas a la profesión. Explora también la dimensión información para indagar en el conocimiento social que los sujetos han aprehendido en su contexto social, respecto a la docencia. De esta manera, avanzar en la reconstrucción de la interpretación del campo de representación de la profesión que han elegido estudiar (Abric, 2001).

\section{Acerca de la formación inicial docente en Chile}

Hoy se experimenta en el país una intensa discusión acerca del Proyecto de Ley de Nueva Carrera Docente que ha puesto el énfasis en aspectos como, por ejemplo, la formación inicial, la carrera profesional docente, la inducción al ejercicio profesional docente (Sánchez, 2013; Ruffinelli, 2017 y Medina, 2018), el sistema de remuneraciones y contratación (Craig, 2016), o las condiciones para el desempeño docente y la transición misma al nuevo sistema.

En este contexto, confluyen una cantidad considerable de disciplinas y áreas que aumentan la complejidad de la discusión en el momento de hacer el ejercicio de dar respuesta al porqué existe la necesidad de repensar la formación del profesorado continuamente. Es un problema complejo puesto que estudiar la formación docente implica entender en forma complementaria, sobre todo para el desarrollo de la competencia profesional docente (Pavié, 2011) los diversos modelos de formación, el territorio donde esta se desarrolla, de la cultura escolar en permanente cambio, de la formación inicial docente, de la formación continua, de la identidad del docente, de los perfiles de egreso del profesor y sus respectivas competencias, de la inserción en la sociedad de la información, del uso eficiente de las nuevas tecnologías, etc. Junto con esto, se debe considerar el aumento de las exigencias sociales a los profesores; la distancia 
entre las exigencias a los profesores y las condiciones de trabajo que éstos tienen; los cambios en la relación alumno-profesor, etc. Estamos, entonces, frente a un entorno complejo desde el que se regula, entre otras cosas, también la formación docente. En adición a lo anterior, Montero (2001) indica que muchos de los "problemas" que se presentan en la formación profesional del profesor son persistentes en el tiempo y que ya han sido determinados con bastante anterioridad por varios autores:

“... la profesión de la enseñanza no tiene un cuerpo codificado de conocimientos y habilidades compartidos, una cultura compartida. La ausencia de este cuerpo de conocimientos compartidos -una de las marcas de las profesiones- cuestiona la pertinencia de utilizar el término profesión para la enseñanza. La consideración de la experiencia práctica como la fuente más importante de adquisición de conocimientos y habilidades -situación que configura un saber vulgar técnico, o artesanal pero nunca un saber científico, base del saber profesional- ha conducido durante mucho tiempo a la irrelevancia de la formación para la comunidad académica y los propios profesores" (Montero, 2001, p.87).

En base a lo expresado, considera entonces que la formación del docente se debe entender como la formación para la profesión docente. A este respecto agregamos también que ya desde la década de los ' 80 ha existido una preocupación por investigar acerca de si realmente existe un rasgo profesionalizante en el profesor y cómo se puede canalizar y/o desarrollar esta profesionalidad desde su formación inicial. Así, autores como Marcelo (2016) o Gimeno Sacristán (1982) -sólo por nombrar algunos- se han preocupado por encauzar sus investigaciones a partir de este matiz, señalando lo siguiente:

“... la preparación y emancipación profesional del docente para elaborar crítica, reflexiva y eficazmente un estilo de enseñanza que promueva un aprendizaje significativo en los alumnos y logre un pensamiento-acción innovador, trabajando en equipo con los colegas para desarrollar un proyecto educativo común" (Gimeno Sacristán, 1982, p.87).

El concepto de formación tiene una mayor vinculación con planteamientos formales de procesos didácticos que posibilitan la preparación, capacitación o perfeccionamiento del docente para su desarrollo o mejora profesional desde el inicio de su carrera. Estos procesos y acciones se desarrollan principalmente en contextos institucionalizados, a los que de modo genérico nos referimos cuando hablamos del ámbito o campo de la formación, o formativo. Esta afirmación la refrenda Moral al señalar que “... sin entrar en las polémicas sobre cuál es el modelo de formación más adecuado, los desafíos educativos actuales demuestran la necesidad urgente de programas de formación del profesorado ajustados a la realidad" (Moral, 2010, p.21). De este modo, se puede plantear que Formación Inicial Docente (FID) es entendida como aquel esquema teórico-práctico que sirve como referencia para la conducción del proceso de formación y es posible ser transferido a otros contextos. Este concepto apela a un esquema que contiene la estructura de los programas, entendida como la organización de distintas áreas que componen el proceso de formación (Sánchez, 2013; Marcelo, 2016). Así, podemos observar que en la mayoría de los países OCDE la FID considera una mixtura entre contenido teórico (disciplina), métodos de aprendizaje (conocimiento pedagógico) y experiencia práctica; junto a estos elementos también se consideran elementos tales como el desarrollo de habilidades de investigación (Pavié, 2011).

\section{Acerca del ejercicio profesional docente}

El ejercicio profesional docente, o profesionalidad docente, transita entre la comprensión de la docencia entendida como un arte y la docencia como habilidad adquirida. Núñez (2001) relaciona ejercicio profesional con identidad profesional, e identifica cuatro formas de entenderla, de acuerdo a las fases históricas por las que ha transitado el profesorado en Chile. En una primera fase, y asociado con el protagonismo de la iglesia en la educación, la profesión docente se asocia 
a un apostolado vinculado a un conjunto de virtudes morales. En una segunda etapa, con el surgimiento del estado docente, el profesional de la educación es símil del funcionario público, encuadrado en estructuras estatales. En la fase de la masificación de la enseñanza, el ejercicio profesional docente adquiere un carácter más técnico, basado en la adquisición y desarrollo de competencias profesionales docentes fácilmente logrables. El último periodo, refiere a la existencia de una base de conocimientos distintivos y propios del profesorado, que caracterizarían su profesionalidad. (Ávalos, 2001 y 2014). Así, se establece una discusión en base a:

“...respecto de qué sabe y debe saber un profesor, cuáles son los conocimientos de base que debe poseer, cómo los actualiza y utiliza, en qué condiciones, cómo fortalecer el dominio de ese corpus de saberes fundamentales y cómo fortalecer las buenas prácticas pedagógicas" (Latorre, 2006, p.60).

Lo anterior implica, que la profesionalización dependerá de decisiones políticas, históricas y culturales que signan y condicionan los programas formativos, sus orientaciones, propósitos y contenidos (Marcelo, 2016; Muñoz, González \& Rodríguez, 2018). Dado que el ejercicio profesional se relaciona con el dominio de saberes que fundamentarán su desempeño laboral, es necesario pesquisar las representaciones acerca de lo que es el ejercicio profesional de los futuros docente (Vélaz de Medrano C. \& Vaillant, 2009; Muñoz, López \& Alonso, 2017). Si bien, la profesionalización implica la apropiación de saberes adquiridos en la trayectoria formativa, esta puede verse influenciada por las representaciones que los estudiantes han construido en etapas anteriores. La Formación Inicial Docente (FID) debe procurar espacios de reflexión, actualización y re-conceptualización de los conocimientos y habilidades pedagógicas, para su futuro ejercicio en los nuevos y actuales contextos sociales y culturales (García, Domínguez \& Del Toro Valencia, 2018).

Por otra parte, los países que han intentado precisar los rasgos que definen el ejercicio profesional docente han coincidido en varios elementos que le son comunes y que se consideran básicos en el momento de re-pensar la formación pedagógica y profesional del profesor. Un ejemplo de lo anterior es a partir del principio de imitación de las "mejores prácticas" y el benchmarking, es decir, la premisa que sostiene que lo que da buenos resultados en una organización también los dará en otra. Así, las concepciones más clásicas de lo que constituye el ejercicio profesional docente apuntan a las siguientes características (Pavié, 2011; Correa, 2011; Hargreaves \& Fullan, 2014; Ruffinelli, 2014; Marcelo, 2016; Jerez, Orsini \& Hasbún, 2016; CNA, 2018 y Cabezas et al., 2019): 1) el dominio de un conjunto de contenidos específicos o especializado, experiencia y lenguaje profesional de una especialidad o disciplina como requisito imprescindible para el desarrollo de competencias específicamente docentes. Sólo así es posible ejecutar los procesos de transposición didáctica en función de los saberes previos de los estudiantes y del proyecto educativo de los centros donde se ejecuta la práctica docente; 2) compartir normas comunes de prácticas y trabajar juntos con otros profesionales para resolver casos complejos; 3) el reconocimiento de la mayor autonomía de los centros educativos y la apropiación del diseño y planificación del proceso educativo por parte de los docentes, genera la necesidad de competencias vinculadas a la gestión del trabajo, del liderazgo pedagógico y del trabajo en equipo; 4) el carácter profesional del profesor está en que le sea reconocido su derecho a examinar los problemas o las demandas de su campo de trabajo; a usar a sus conocimientos para decidir formas de acción conducentes a la finalidad perseguida, y a actuar según lo indique el juicio emitido, poniendo en juego sus conocimientos y capacidades prácticas; 5) los estudiantes valoran más el cómo el profesor transmite los conocimientos y cómo les facilita el aprendizaje, sin embargo, esa facilitación requiere además de competencias disciplinares y profesionales; 6 ) el contexto cambiante en el que se desarrolla la enseñanza, la organización del trabajo, las demandas de los destinatarios de la formación y de los centros educativos hace necesario el desarrollo de las competencias relacionadas con la profesionalidad docente y 7) el ejercicio profesional docente requiere continuas adaptaciones y nuevos elementos en el curso del ejercicio de la enseñanza, como resultado de los cambios que ocurren en casi todos los frentes: demandas 
sociales, nuevos currículos, estudiantes que cambian de un contexto a otro, nuevas tecnologías, etc.

Considerando lo anteriormente expuesto, también se debe tomar en cuenta elementos que la literatura en relación al contexto de la profesión y el ejercicio docente en el sentido de que persiste la lentitud de los sistemas educativos para generar estructuras apropiadas que satisfagan las nuevas demandas Esto, a su vez, afecta el ejercicio profesional de los profesores y la posibilidad de cumplir con las expectativas que se tiene de ellos. En América Latina, incluyendo a Chile y países pobres de otras regiones, el abandono de la carrera es menos frecuente en la medida en que no existan mejores oportunidades laborales alternativas, pero el nivel bajo de quienes ingresan a la docencia, junto con lo anterior, los profesores estudiados tienden a sentir mayor satisfacción cuando su labor es reconocida y apreciada, y existen buenas relaciones entre colegas (Sánchez, 2013; Ruffinelli, 2014; Rosso, \& Alcalá, 2016; Marcelo, 2016; Jarauta, 2017).

\section{Método}

Tal como señalan Taylor y Bogdan (1990) lo que define la metodología es tanto la manera de focalizar los problemas como la forma de buscar las respuestas a los mismos. Por ello, en coherencia con los objetivos del estudio, el diseño de la presente investigación es de tipo descriptivo interpretativo, puesto que pretende caracterizar las representaciones de los sujetos (objetos de la investigación) y alcanzar una interpretación de ellas desde los supuestos teóricos adoptados en la indagación. En otras palabras, se elaboraron arquetipos interpretativos de las representaciones de los actores involucrados para la formulación de hipótesis interpretativas (Goetz, y LeCompte, 1988; Eisner, 1998; Latorre, Del Rincón \& Amal. 1997; Neiman \& Quaranta, 2006). Desde el punto de vista temporal, el estudio fue de tipo transversal, dado que la recolección de información se realizó una sola vez a todos los estudiantes matriculados en primer año en alguna de las carreras de Pedagogía de la Universidad, quienes contestaron en el mismo momento haciendo uso de soportes informáticos. La consulta se realizó durante el mes de abril del 2018, siguiendo protocolo de consentimiento informado y confidencialidad de información (Meo, 2010), en coherencia con la política institucional al respecto.

\section{Población y muestra}

La población objetivo correspondió a estudiantes de primer año de carreras pedagógicas matriculados el año 2019 en siete Universidades Estatales de Chile, las cuales fueron clasificadas en Macrozona Norte, Centro Norte, Centro Sur, Macrozona sur y Macrozona Austral. Para ello se consideró una muestra probabilística por Macrozona, considerando los criterios del tamaño de la población objetivo de cada una de ellas, un margen de error del $5 \%$, una heterogeneidad del $50 \%$ y un nivel de confianza del $95 \%$. De acuerdo a la matrícula informada al Servicio de Información de la Educación Superior (SIES), con fecha de corte al 30 de abril del año 2019, la población de matrícula registrada en carreras Profesionales con Licenciatura en carreras de pedagogías, en las siete universidades consideradas para el estudio fue de 2218 estudiantes, por lo que la muestra total a la que se logró llegar fue 1836 , lo que equivale a un $82,8 \%$ de los estudiantes de primer año matriculados en carreras de pedagogías, esto se puede observar en la tabla 1, la cual muestra el detalle por Macrozona. Para el caso de la Macrozona norte, posterior al 30 de abril se han registrado más estudiantes matriculados, por lo que el porcentaje de cobertura es mayor a la población inicial. 
Tabla 1.

Población y Muestra obtenida

\begin{tabular}{ccccc}
\hline Macrozona & $\begin{array}{c}\text { Población al 30 } \\
\text { de abril 2019 }\end{array}$ & $\begin{array}{c}\text { Muestra } \\
\text { Determinada }\end{array}$ & $\begin{array}{c}\text { Muestra } \\
\text { Final } \\
\text { Obtenida }\end{array}$ & $\begin{array}{c}\text { Porcentaje de } \\
\text { representatividad }\end{array}$ \\
\hline $\begin{array}{c}\text { Macrozona } \\
\text { Norte }\end{array}$ & 498 & 217 & 502 & $100.8 \%$ \\
$\begin{array}{c}\text { Macrozona } \\
\text { Centro Norte }\end{array}$ & 793 & 259 & 712 & $89.8 \%$ \\
$\begin{array}{c}\text { Macrozona } \\
\text { Centro Sur }\end{array}$ & 473 & 212 & 232 & $49.0 \%$ \\
$\begin{array}{c}\text { Macrozona Sur } \\
\text { Macrozona } \\
\text { Austral } \\
\text { Total }\end{array}$ & 368 & 188 & 309 & $84.0 \%$ \\
Macrozonas & 86 & 70 & 81 & $94.2 \%$ \\
\hline
\end{tabular}

Nota: Elaboración propia. Para el cazo de la Macrozona Norte, posterior al 30 de abril se contabilizaron más estudiantes matrículados.

\section{Instrumento}

En coherencia con los objetivos del estudio, los investigadores diseñaron un instrumento de escala tipo Likert denominada "Escalas de Representaciones sobre la Profesión Docente" ${ }^{1}$. Constó de seis dimensiones y un total de 51 ítems que se segmentó en seis dimensiones: Vocacional, desarrollo profesional y económico, políticas educativas, ejercicio profesional, auto imagen y prestigio social, y formación de profesores. Para la dimensión de Ejercicio Profesional los diez ítems asociados se muestran en la tabla 2. Para el presente estudio se enfocará en la dimensión de Ejercicio Profesional debido a que en trabajos posteriores se abordarán en específico el análisis de las otras dimensiones de este estudio presentado.

\section{Tabla 2.}

Tabla de especificaciones Escala de Representaciones sobre la Profesión Docente

\begin{tabular}{lc}
\hline \multicolumn{1}{c}{ Dimensión } & Escalas \\
\hline Vocacional & 8 \\
Desarrollo Profesional y Económico & 8 \\
Políticas Educativas & 9 \\
Ejercicio Profesional & 10 \\
Auto-Imagen y Prestigio Social & 8 \\
Formación de Profesores. & 8 \\
Total ítems & 51 \\
\hline
\end{tabular}

Nota: Elaboración propia.

La escala presenta un conjunto de proposiciones o afirmaciones para cada dimensión, con categorías escalonadas que van desde desfavorable a lo favorable (Totalmente en Desacuerdo, En Desacuerdo, De acuerdo, Totalmente De Acuerdo, Sin información del Tema). Al contestar, los sujetos evaluados debían graduar su respuesta, ubicándose en algún punto de la escala según sus propias representaciones a nivel de información y valoración ${ }^{2}$. Por tanto, cada afirmación proporciona datos sobre la dimensión evaluada. En este caso, la frecuencia de las respuestas de

\footnotetext{
${ }^{1}$ La autoría del instrumento es de los académicos Autores. 2017.

${ }^{2}$ Para el presente artículo se presentarán los resultados de la dimensión Ejercicio Profesional
} 
las escalas que contemplan cada dimensión permite identificar la tendencia sobre ella. El tiempo de respuesta del instrumento es de 45 minutos aproximadamente.

Para efectos del estudio, el instrumento fue sometido a validación de contenido y validación estadística durante el año 2017. En la validación de contenido, participaron académicos de las Universidades de Playa Ancha y del Bío-Bío como jueces expertos. Para la validación estadística se calculó el coeficiente Alpha Cronbach (0.82) y el Kaiser-Meyer-Olkin (0.87) en una muestra de 1.789 estudiantes matriculados en carreras de primer año de pedagogía de Universidades del Estados del país (Autores 2017). En el presente estudio, se vuelve a calcular el Alpha Cronbach (0.90) y Kaiser-Meyer-Olkin (0.902), en base a los 1836 sujetos de las diferentes Universidades, obteniendo resultados similares a 2017 y 2018, lo que permite inferir que el instrumento posee una robustez y consistencia interna en el tiempo; por tanto, es posible sostener que la información obtenida resulta confiable para los efectos del presente estudio.

Una segunda parte del instrumento, estaba enfocada en determinar los conceptos que los estudiantes consideran sobre la profesión docente, en dónde debían jerarquizar en orden preferencia las categorías presentadas en las dos preguntas, la primera enfocada en los principales conocimientos que debe saber un profesor para un adecuado ejercicio de su profesión y la segunda pregunta en que las principales habilidades que debe tener un profesor para un adecuado ejercicio de su profesión.

\section{Variables}

La cantidad de variables que compone el instrumento es de un total 51, para la dimensión de ejercicio profesional existe un total de 10 ítems, los cuales se pueden visualizar en la tabla 3. Las variables son categóricas de tipo ordinal, medidas en escala Likert, las cuales correspondieron a; Totalmente en desacuerdo, en Desacuerdo, Sin información del tema, de Acuerdo y Totalmente de Acuerdo.

Tabla 3.

Ítems de la Dimensión Ejercicio Profesional

\begin{tabular}{|c|c|}
\hline ítem & Pregunta \\
\hline ítem 26 & $\begin{array}{l}\text { El Profesor(a) es responsable de motivar a sus estudiantes en el proceso enseñanza } \\
\text { aprendizaje en el aula. }\end{array}$ \\
\hline ítem 27 & El Profesor(a) representa la autoridad de la sociedad en la sala de clase. \\
\hline ítem 28 & Un Profesor(a) trasmite el conocimiento de la sociedad en la sala de clase. \\
\hline ítem 29 & Un Profesor(a) comunica el conocimiento cultural en la sala de clase. \\
\hline ítem 30 & $\begin{array}{l}\text { Planificar es uno de las principales funciones-tareas de los Profesores (as) en el sistema } \\
\text { escolar. }\end{array}$ \\
\hline ítem 31 & $\begin{array}{l}\text { Calificar es una de las principales funciones de los Profesores (as) en el sistema } \\
\text { escolar. }\end{array}$ \\
\hline ítem 32 & $\begin{array}{l}\text { El Profesor(a) debe ser modelo de conducta y valores en el establecimiento escolar y el } \\
\text { aula para sus alumnos. }\end{array}$ \\
\hline ítem 33 & $\begin{array}{l}\text { El Profesor(a) es un modelo de sabiduría y conocimiento en el establecimiento escolar } \\
\text { y el aula para sus estudiantes. }\end{array}$ \\
\hline ítem 34 & $\begin{array}{l}\text { El Profesor (a) debe considerar a la familia, la sociedad, el grupo de pares y los medios } \\
\text { de comunicación como fuente o referentes para optimizar los aprendizajes. }\end{array}$ \\
\hline Ítem35 & $\begin{array}{l}\text { El Profesor (a) debe tener altas capacidades cognitivas y de personalidad para el } \\
\text { desarrollo de la profesión docente }\end{array}$ \\
\hline
\end{tabular}

Nota: Elaboración propia. 


\section{Procedimientos de análisis de la información}

Dado que el instrumento de recolección de información responde a una escala tipo Likert, a fin de develar las representaciones sobre la profesión docente que han construido los estudiantes que ingresan a estudiar alguna de las carreras de Pedagogía, presupone que no existen respuestas correctas o incorrectas en relación con el objeto de estudio. En coherencia, se utilizaron métodos descriptivos numéricos (porcentajes, frecuencias, etc.) con el propósito de facilitar la identificación de la tendencia o las representaciones dominantes. Específicamente, para tales efectos, las repuestas marcadas por los sujetos se agruparon en: respuestas positivas (De acuerdo y Totalmente De Acuerdo), respuestas neutras (Sin información del Tema) y respuestas negativas (Totalmente en Desacuerdo y En Desacuerdo).

Para el análisis de datos se utilizó el Software SPSS versión 21, los métodos utilizados corresponden a estadística descriptiva e inferencial. De acuerdo a la clasificación de las variables, las cuales corresponden a variables categóricas ordinales y nominales, no es posible dentro de la estadística descriptiva utilizar los estadísticos como media, desviación estándar, entre otros, por lo que se enfoca en las frecuencias de distribución de las respuestas obtenidas, por otro lado en términos de la estadística inferencial se usaron las pruebas no paramétricas de U de Mann Whitney y Kruskal Wallis, con el propósito de establecer diferencias significativas en los análisis realizados (Gorgas, Cardiel \& Zamorano, 2011). Se debe tener en consideración que: las universidades se agruparon según Macrozona geográfica, las que en definitiva son: Macrozona Norte, Centro Norte, Centro Sur, Macrozona Sur y Macrozona Austral.

\section{Resultados: caracterización de la muestra}

A continuación, se muestran resultados de la caracterización general de los estudiantes de pedagogías que respondieron el cuestionario. En términos generales, de un total de 1836 estudiantes de carreras de pedagogía que ingresaron el año 2019 en siete universidades a lo largo de Chile, se tiene que el 61.3\% (1125) corresponde a mujeres y un 37.3\% (684) a hombres, sólo un $1.5 \%$ (27) prefirió no contestar. Respecto a la procedencia de los estudiantes, el 56\% (1029) declaran que provienen de un establecimiento Municipal, un 40.6\% (746) de establecimientos Particular Subvencionado y solo un 3.3\% (61) de los provienen de establecimientos Particulares Pagados. De acuerdo a la zona dónde se encontraban los establecimientos, el 89.6\% (1645) indica que su establecimiento se encontraba en la zona Urbana y un $10.4 \%$ (191) en zona Rural.

Sobre la vía de ingreso utilizada por los estudiantes, para ingresar a una carrera pedagógica, el 85\% (1561) ingresa bajo la vía de Admisión Normal o Regular (PSU), seguido por un 4.4\% (64) que ingresaron a través del programa Talento Pedagógico. Por otro lado, se tiene que el $80.8 \%$ (1501) postuló a la carrera en primera preferencia y un 12\% (220) en segunda preferencia, sólo un $7.2 \%$ (115) postuló en otra preferencia. Al analizar los ingresos se tiene que el $17.3 \%$ (318) y el $17.5 \%$ (321) de los estudiantes declaran que su grupo familiar tiene un ingreso bruto entre $\$ 255.001$ a $\$ 320.000$ y $\$ 320.001$ a $\$ 435.000$ respectivamente. Un $1.2 \%$ (22) de la muestra menciona tener problemas de discapacidad. Un $24.7 \%$ (454) declara que se considera perteneciente algún pueblo indígena u originario. El 98.7\% (1813) de los estudiantes declara tener nacionalidad chilena. Se tiene, además, que el $40.7 \%$ (748) de los estudiantes declara que tiene algún familiar que haya sido o es educador(a).

De los 10 ítems que componen la dimensión de ejercicio profesional docente, 8 de ellos tienen más del $90 \%$ de acuerdo en que el profesor(a) es responsable de motivar a sus estudiantes en el proceso enseñanza en el aula, que debe transmitir conocimiento de la sociedad y conocimiento cultural en clases, que planificar es una de la principales tareas, que el profesor(a) debe ser modelo de conducta, valores, sabiduría y conocimiento en el establecimiento escolar y en aula para sus alumnos, que el profesor(a) debe considerar a la familia, sociedad, el grupo de pares y los medios de comunicación como fuente o referente para optimizar los aprendizajes y 
por último que debe tener altas capacidades cognitivas y de personalidad para el desarrollo de la profesión docente.

En las otras dos preguntas asociadas a la dimensión su valoración positiva llega a un $76.9 \%$ en que el profesor representa la autoridad de la sociedad en una sala de clases, y un 56.9\% en sobre si las calificaciones son una de las principales funciones del profesor, la distribución de las respuestas puede observarse en la figura 1 .

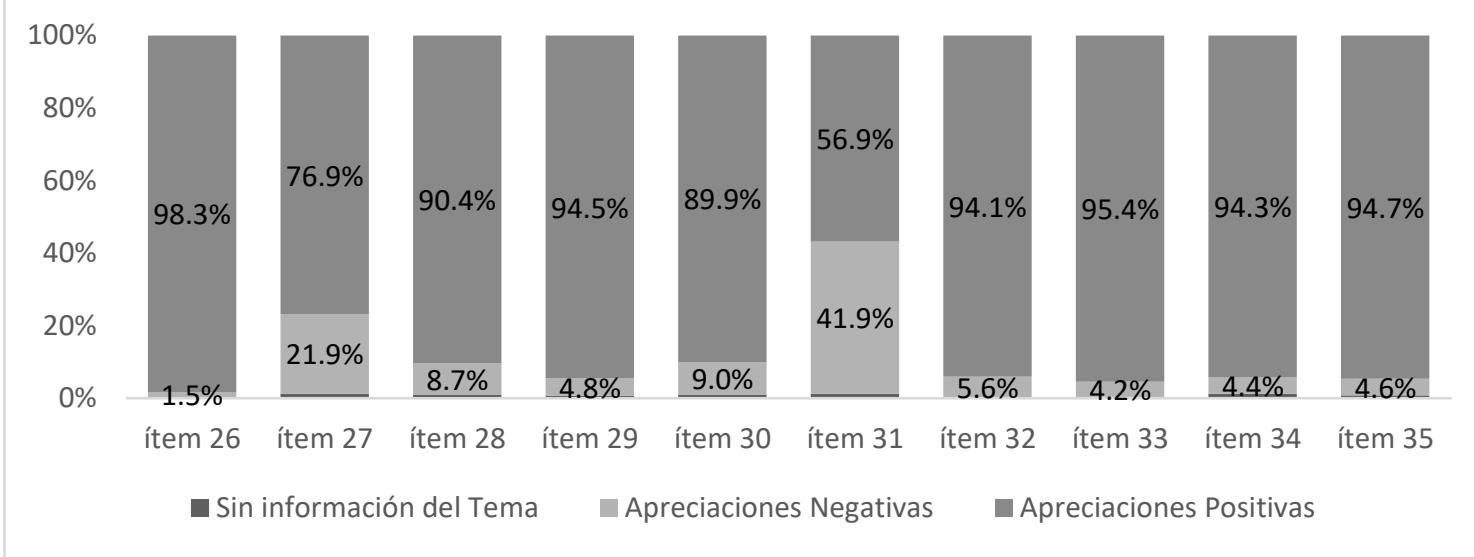

Figura 1. Distribución de las respuestas de la dimensión ejercicio profesional por ítem

Al determinar si existen diferencias significativas en las distribuciones de respuesta entre hombres y mujeres se tiene que sólo en dos ítems de la dimensión se presentan diferencias significativas en la distribución de respuestas, por lo que en la opción de si el profesor(a) es responsable de motivar a sus estudiantes en el proceso enseñanza aprendizaje en el aula, hombres y mujeres mantiene una diferencia en la distribución de respuestas $(p<0.001)$ y en que el profesor(a) debe ser modelo de conducta y valores en el establecimiento escolar y el aula para sus alumnos ( $\mathrm{p}<0.001)$, la distribución de respuestas por cada ítem puede visualizarse en la tabla 4. 
Tabla 4.

Representaciones por género en la dimensión ejercicio docente.

\begin{tabular}{lrrrrrr}
\hline Ítem & $\begin{array}{c}\text { Sin } \\
\text { información } \\
\text { del Tema }\end{array}$ & $\begin{array}{c}\text { Apreciaciones } \\
\text { Negativas }\end{array}$ & $\begin{array}{c}\text { Apreciaciones } \\
\text { Positivas }\end{array}$ & $\begin{array}{c}\text { Sin } \\
\text { información } \\
\text { del Tema }\end{array}$ & $\begin{array}{c}\text { Apreciaciones } \\
\text { Negativas }\end{array}$ & $\begin{array}{l}\text { Apreciaciones } \\
\text { Positivas }\end{array}$ \\
\hline ítem 26 & $0,0 \%$ & $1,0 \%$ & $99,0 \%$ & $0.4 \%$ & $2.3 \%$ & $97.2 \%$ \\
ítem 27 & $1,0 \%$ & $20.9 \%$ & $78.1 \%$ & $1.6 \%$ & $22.5 \%$ & $75.9 \%$ \\
ítem 28 & $1.1 \%$ & $8.9 \%$ & $90,0 \%$ & $0.6 \%$ & $8.3 \%$ & $91.1 \%$ \\
ítem 29 & $0.7 \%$ & $4.4 \%$ & $94.8 \%$ & $0.6 \%$ & $5.4 \%$ & $94,0 \%$ \\
ítem 30 & $1.1 \%$ & $9.9 \%$ & $89.1 \%$ & $0.9 \%$ & $7.7 \%$ & $91.4 \%$ \\
ítem 31 & $1.2 \%$ & $40.7 \%$ & $58.1 \%$ & $1.5 \%$ & $43.1 \%$ & $55.4 \%$ \\
ítem 32 & $0.2 \%$ & $4,0 \%$ & $95.8 \%$ & $0.4 \%$ & $7.3 \%$ & $92.3 \%$ \\
ítem 33 & $0.5 \%$ & $3.4 \%$ & $96.1 \%$ & $0.3 \%$ & $4.7 \%$ & $95,0 \%$ \\
ítem 34 & $1.4 \%$ & $3.6 \%$ & $95,0 \%$ & $1.2 \%$ & $5.4 \%$ & $93.4 \%$ \\
ítem 35 & $0.8 \%$ & $4.1 \%$ & $95.1 \%$ & $0.7 \%$ & $5.4 \%$ & $93.9 \%$ \\
\hline
\end{tabular}

Nota: Elaboración propia.

\section{Resultados por Macrozona}

$\mathrm{Al}$ analizar los resultados por Macrozona, es relevante mencionar que en el ítem 27, sobre si el profesor representa la autoridad de la sociedad en una sala de clases, en la Zona norte un 13\% están en desacuerdo con esta afirmación, un $27.7 \%$ en la Macrozona Centro norte, $22.8 \%$ en la Macrozona Centro Sur, un 22.3\% en la Macrozona Sur y un 22\% en la Austral, lo que se puede visualizar en la tabla 5. En este mismo ítem se detectaron cuatro diferencias significativas al comparar Macrozonas, quienes presentaron diferencias significativas al 5\% en la distribución de respuestas, las cuales corresponden a la Macrozona Norte con Centro Norte ( $\mathrm{p}<.0 .001)$; Norte con Centro sur $(p<.0 .001)$; Macrozona Norte con Macrozona Sur $(p<.0 .001)$; Norte con Austral $(\mathrm{p}<.0 .001)$. 
Tabla 5.

Representaciones por Macrozona en la dimensión ejercicio docente, todos los valores son expresados en porcentajes.

\begin{tabular}{|c|c|c|c|c|c|c|c|c|c|c|c|c|c|c|c|}
\hline \multirow[t]{2}{*}{ Ítem } & \multirow[b]{2}{*}{$\mathbf{S} / \mathbf{i}$} & \multicolumn{3}{|c|}{$\begin{array}{l}\text { Macrozona } \\
\text { Norte }\end{array}$} & \multicolumn{3}{|c|}{$\begin{array}{l}\text { Macrozona } \\
\text { Centro Norte }\end{array}$} & \multicolumn{2}{|c|}{$\begin{array}{l}\text { Macrozona } \\
\text { Centro Sur }\end{array}$} & \multicolumn{3}{|c|}{$\begin{array}{l}\text { Macrozona } \\
\text { Sur }\end{array}$} & \multicolumn{3}{|c|}{$\begin{array}{l}\text { Macrozona } \\
\text { Austral }\end{array}$} \\
\hline & & - & + & $\mathbf{S} / \mathbf{i}$ & - & + & $\mathbf{S} / \mathbf{i}$ & - & + & $\mathbf{S} / \mathbf{i}$ & - & + & $\mathbf{S} / \mathbf{i}$ & - & + \\
\hline 26 & 0.0 & 1.0 & 99.0 & 0.1 & 1.4 & 98.5 & 0.4 & 1.7 & 97.8 & 0,0 & 2.3 & 97.7 & 1.2 & 2.5 & 96.3 \\
\hline 27 & 0.2 & 12.9 & 86.9 & 1.7 & 27.7 & 70.6 & 0.4 & 22.8 & 76.7 & 2.3 & 22.3 & 75.4 & 2.5 & 22.2 & 75.3 \\
\hline 28 & 1.0 & 7.2 & 91.8 & 0.7 & 9.0 & 90.3 & 1.7 & 11.6 & 86.6 & 0.6 & 7.8 & 91.6 & 0.0 & 11.1 & 88.9 \\
\hline 29 & 0.8 & 3.4 & 95.8 & 0.8 & 5.2 & 94.0 & 0.4 & 8.6 & 90.9 & 0.3 & 3.9 & 95.8 & 0.0 & 3.7 & 96.3 \\
\hline 30 & 0.8 & 4.8 & 94.4 & 0.6 & 9.8 & 89.6 & 2.6 & 10.8 & 86.6 & 1.6 & 12.9 & 85.4 & 0.0 & 8.6 & 91.4 \\
\hline 31 & 1.2 & 31.9 & 66.9 & 0.8 & 50.4 & 48.7 & 2.2 & 47.4 & 50.4 & 1.6 & 37.2 & 61.2 & 1.2 & 30.9 & 67.9 \\
\hline 32 & 0.0 & 3.8 & 96.2 & 0.3 & 6.7 & 93.0 & 0.4 & 5.6 & 94.0 & 0.3 & 7.1 & 92.6 & 1.2 & 1.2 & 97.5 \\
\hline 33 & 0.0 & 3.4 & 96.6 & 0.6 & 3.8 & 95.6 & 0.9 & 6.5 & 92.7 & 0.6 & 5.8 & 93.5 & 0.0 & 0.0 & $\begin{array}{l}100 \\
0\end{array}$ \\
\hline 34 & 1.2 & 4.4 & 94.4 & 1,0 & 3.5 & 95.5 & 1.7 & 5.2 & 93.1 & 2.3 & 7.1 & 90.6 & 0.0 & 0.0 & $\begin{array}{l}100 \\
0\end{array}$ \\
\hline 35 & 0.2 & 4.4 & 95.4 & 1.3 & 3.9 & 94.8 & 1.7 & 7.3 & 90.9 & 0.0 & 4.2 & 95.8 & 0.0 & 4.9 & 95.1 \\
\hline
\end{tabular}

Nota: Elaboración propia. S/I corresponde a sin información del tema, - respuestas negativas y + respuestas positivas.

En el ítem 31 sobre si las calificaciones son una de las principales funciones del profesor, en la Zona norte un 32\% de los estudiantes están en desacuerdo con esta afirmación, un $50.4 \%$ en la Macrozona Centro norte, $47.4 \%$ en la Macrozona Centro Sur, un 37.2\% en la Macrozona Sur y un $30.9 \%$ en la Austral. En este mismo ítems se detectaron seis diferencias significativas al comparar Macrozonas, quienes presentaron diferencias significativas al 5\% en la distribución de respuesta corresponde a la Macrozona Norte con Centro Norte $(\mathrm{p}<0.001)$; Norte con Centro sur ( $p<.0 .001)$; Macrozona Centro Norte con Macrozona Sur ( $p<.0 .001)$; Centro Norte Norte con Austral ( $\mathrm{p}<.0 .001)$; Macrozona Centro Sur con Macrozona Sur ( $\mathrm{p}<.0 .001)$ y Macrozona Centro Sur con Macrozona Austral ( $\mathrm{p}=.0 .007)$. Si bien se detectaron otras diferencias en la distribución de respuestas, aquellas que presentaron un comportamiento notoriamente distinto al resto de los ítems fue en el ítem 27 sobre si el profesor representa la autoridad de la sociedad en una sala de clases y en el ítem 31 sobre si las calificaciones son una de las principales funciones del profesor, en la tabla 6 se pueden observar las significancias obtenidas por cada par de comparación entre Macrozonas.

Tabla 6.

Significancias de la prueba Kruskal-Wallis comparando Macrozonas

\begin{tabular}{|c|c|c|c|c|c|c|c|c|c|c|}
\hline Ítem & $\begin{array}{c}\text { Norte } \\
- \\
\text { Centr } \\
0 \\
\text { Norte }\end{array}$ & $\begin{array}{l}\text { Norte } \\
- \\
\text { Centr } \\
\text { o Sur }\end{array}$ & $\begin{array}{l}\text { Norte } \\
\text {-Sur }\end{array}$ & $\begin{array}{c}\text { Norte } \\
- \\
\text { Austr } \\
\text { al }\end{array}$ & $\begin{array}{c}\text { Centro } \\
\text { Norte- } \\
\text { Centro } \\
\text { Sur }\end{array}$ & $\begin{array}{c}\text { Centr } \\
\text { o } \\
\text { Norte } \\
\text {-Sur }\end{array}$ & $\begin{array}{l}\text { Centro } \\
\text { Norte- } \\
\text { Austral }\end{array}$ & $\begin{array}{l}\text { Centro } \\
\text { Sur- } \\
\text { Sur }\end{array}$ & $\begin{array}{c}\text { Centro } \\
\text { Sur- } \\
\text { Austra } \\
1\end{array}$ & $\begin{array}{c}\text { Sur- } \\
\text { Austra } \\
1\end{array}$ \\
\hline 26 & .408 & .206 & 0.14 & 0.051 & 0.53 & 0.424 & 0.16 & 0.937 & 0.445 & 0.458 \\
\hline 27 & 0.000 & 0.001 & 0.00 & 0.00 & 0.0 & 0.14 & 414 & 0. & & 0.979 \\
\hline 28 & 0.375 & 0.028 & 0.91 & 0.399 & 0.1 & 0.5 & 0.701 & 0.061 & 0.5 & 0.463 \\
\hline 29 & 0.157 & 0.009 & 0.99 & 0.831 & 0.119 & 0.234 & 0.388 & 0.022 & 0.11 & 0.835 \\
\hline 30 & 0.003 & 0.000 & 0.00 & 0.293 & & 0.052 & & 0.731 & & 0.154 \\
\hline 31 & 0.000 & 0.000 & 0.09 & 0.86 & 0.7 & 0.000 & 01 & 0.01 & 0.0 & 0.265 \\
\hline 32 & 0.016 & 0.169 & 0.02 & 0.57 & 0.608 & 0.81 & 0.124 & 0.525 & 0.219 & 0.11 \\
\hline 33 & 0.385 & 0.017 & 0.04 & 0.093 & 0.074 & 0.155 & 0.056 & 0.694 & 0.012 & 0.019 \\
\hline 34 & 0.392 & 0.48 & 0.03 & 0.0 & & 0.002 & 0.052 & 0.301 & & 0.004 \\
\hline 35 & 0.600 & 0.016 & 0.79 & 0.89 & 0.035 & 0.478 & 0.902 & 0.02 & 0.231 & 0.774 \\
\hline
\end{tabular}

Nota: Elaboración propia. 


\section{Resultados por Tipo de Establecimiento}

Al determinar los resultados del ejercicio profesional por tipo de establecimiento se detecta el mismo comportamiento tanto como a nivel global, por género y por Macrozona, el cual está en torno al ítem 27 y 28 resultados que se pueden visualizar en la tabla 7. Por tanto, sobre si el profesor representa la autoridad de la sociedad en una sala de clases, en estudiantes provenientes de establecimientos municipales un $21.4 \%$ están en desacuerdo con esta afirmación, un $21.2 \%$ en aquellos que provienen de establecimientos subvencionados y un $37.7 \%$ en estudiantes de establecimientos particulares pagados no están de acuerdo. En esta misma afirmación se detectaron dos diferencias significativas al comparar tipos de establecimiento, quienes presentaron diferencias significativas al 5\% en la distribución de respuesta la cual correspondió al comprar los establecimientos Públicos con el subvencionados ( $\mathrm{p}=.0 .013)$ y los establecimientos subvencionados con particular pagado $(\mathrm{p}=.0 .008)$.

Tabla 7.

Representaciones por Tipo de Establecimiento en la dimensión ejercicio docente

\begin{tabular}{lcrrrrrrrr}
\hline & \multicolumn{3}{c}{ Municipal } & \multicolumn{4}{c}{ Subvencionado } & \multicolumn{3}{c}{ Pagado } \\
\hline & S/i & - & \multicolumn{1}{c}{+} & \multicolumn{1}{c}{ S/i } & - & $\boldsymbol{+}$ & \multicolumn{1}{c}{ S/i } & - & + \\
ítem 26 & $0.3 \%$ & $1.9 \%$ & $97.9 \%$ & $0.1 \%$ & $1.4 \%$ & $98.5 \%$ & $0,0 \%$ & $0,0 \%$ & $100,0 \%$ \\
ítem 27 & $1.5 \%$ & $21.4 \%$ & $77.1 \%$ & $1.2 \%$ & $21.3 \%$ & $77.6 \%$ & $0,0 \%$ & $37.7 \%$ & $62.3 \%$ \\
ítem 28 & $0.7 \%$ & $8.8 \%$ & $90.5 \%$ & $1.1 \%$ & $8.1 \%$ & $90.9 \%$ & $0,0 \%$ & $18,0 \%$ & $82,0 \%$ \\
ítem 29 & $0.7 \%$ & $4.7 \%$ & $94.6 \%$ & $0.7 \%$ & $4.5 \%$ & $94.8 \%$ & $0,0 \%$ & $13.1 \%$ & $86.9 \%$ \\
ítem 30 & $1.3 \%$ & $9.8 \%$ & $88.9 \%$ & $0.8 \%$ & $8.8 \%$ & $90.4 \%$ & $1.6 \%$ & $3.3 \%$ & $95.1 \%$ \\
ítem 31 & $1.6 \%$ & $37.4 \%$ & $61,0 \%$ & $1.1 \%$ & $44.8 \%$ & $54.1 \%$ & $0,0 \%$ & $47.5 \%$ & $52.5 \%$ \\
ítem 32 & $0.4 \%$ & $4.3 \%$ & $95.3 \%$ & $0.2 \%$ & $6.7 \%$ & $93.1 \%$ & $0,0 \%$ & $3.3 \%$ & $96.7 \%$ \\
ítem 33 & $0.7 \%$ & $4.6 \%$ & $94.8 \%$ & $0.3 \%$ & $3.9 \%$ & $95.8 \%$ & $0,0 \%$ & $4.9 \%$ & $95.1 \%$ \\
ítem 34 & $1.3 \%$ & $4.2 \%$ & $94.5 \%$ & $1.4 \%$ & $4.6 \%$ & $94.1 \%$ & $0,0 \%$ & $4.9 \%$ & $95.1 \%$ \\
ítem 35 & $0.8 \%$ & $4.2 \%$ & $95,0 \%$ & $0.8 \%$ & $4.8 \%$ & $94.5 \%$ & $0,0 \%$ & $6.6 \%$ & $93.4 \%$ \\
\hline
\end{tabular}

Nota: Elaboración propia. S/I corresponde a sin información del tema, - respuestas negativas y + respuestas positivas.

Sobre si las calificaciones son una de las principales funciones del profesor, asociado al ítem 31 se tiene que en estudiantes provenientes de establecimientos municipales un $37.4 \%$ están en desacuerdo con esta afirmación, un $44.8 \%$ en aquellos que provienen de establecimientos subvencionados y un $47.5 \%$ en estudiantes de establecimientos particulares pagados no están de acuerdo. En esta misma afirmación se detectó solo una diferencia significativa al comparar tipos de establecimiento, en este caso quien presento la diferencia en la distribución de respuestas fueron estudiantes de establecimientos públicos con establecimientos particulares subvencionados $(\mathrm{p}=.0 .006)$. Si bien se detectaron otras diferencias en la distribución de respuestas, lo que se puede visualizar en la tabla 8 , aquellas que presentaron un comportamiento notoriamente distinto al resto de los ítems fue sobre si el profesor representa la autoridad de la sociedad en una sala de clases y si las calificaciones son una de las principales funciones del profesor. 
Tabla 8

Significancias de la prueba Kruskal-Wallis comparando tipos de establecimientos

\begin{tabular}{cccc}
\hline & $\begin{array}{c}\text { Público- } \\
\text { Subvencionado }\end{array}$ & Público- Particular & Subvencionado-Particular \\
\hline ítem 26 & 0.274 & 0.248 & 0.343 \\
ítem 27 & 0.79 & 0.013 & 0.008 \\
ítem 28 & 0.807 & 0.037 & 0.025 \\
ítem 29 & 0.845 & 0.015 & 0.009 \\
ítem 30 & 0.289 & 0.139 & 0.233 \\
ítem 31 & 0.006 & 0.236 & 0.86 \\
ítem 32 & 0.055 & 0.609 & 0.271 \\
ítem 33 & 0.293 & 0.908 & 0.784 \\
ítem 34 & 0.703 & 0.832 & 0.728 \\
ítem 35 & 0.594 & 0.598 & 0.75 \\
\hline
\end{tabular}

Nota: Elaboración propia.

\section{Resultados de la jerarquización de conceptos}

De acuerdo con la jerarquización de conceptos, las preguntas estaban enfocadas a los conceptos que consideran los estudiantes sobre la profesión docente, ellos debían elegir la preferencia por cada categoría presentada. En términos globales tanto las categorías como las preferencias son consideradas como variables respuestas, por lo que se realizaron tablas de contingencia considerando porcentajes filas y columnas para una mejor descripción.

\section{Tabla 9}

Jerarquización de Conceptos con respecto a los conocimientos para un adecuado ejercicio de la profesión

\begin{tabular}{lrrrrrrr}
\hline & $\mathbf{1}^{\circ}$ & \multicolumn{1}{c}{$\mathbf{2}^{\circ}$} & \multicolumn{1}{c}{$\mathbf{3}^{\circ}$} & \multicolumn{1}{c}{$\mathbf{4}^{\circ}$} & $\mathbf{5}^{\circ}$ & \multicolumn{1}{c}{$\mathbf{6}^{\circ}$} & $\mathbf{7}^{\circ}$ \\
\hline Psicología Educativa & $44.2 \%$ & $28.6 \%$ & $15.3 \%$ & $6.3 \%$ & $3.1 \%$ & $1.7 \%$ & $0.8 \%$ \\
Sociología de la Educación & $11.5 \%$ & $28.9 \%$ & $26.4 \%$ & $18.9 \%$ & $8.9 \%$ & $4.6 \%$ & $0.8 \%$ \\
Filosofía y Ética & $12,0 \%$ & $16,0 \%$ & $24.4 \%$ & $22.6 \%$ & $14.3 \%$ & $9.5 \%$ & $1.1 \%$ \\
Didáctica & $15.4 \%$ & $15.6 \%$ & $20.3 \%$ & $27.1 \%$ & $16.1 \%$ & $4.6 \%$ & $0.9 \%$ \\
Evaluación & $2.9 \%$ & $4.1 \%$ & $6.4 \%$ & $14.4 \%$ & $33.7 \%$ & $30.9 \%$ & $7.6 \%$ \\
Currículum & $8.2 \%$ & $4.5 \%$ & $5.3 \%$ & $7.3 \%$ & $19.6 \%$ & $44.3 \%$ & $10.8 \%$ \\
Otro. ¿Cuál? & $5.8 \%$ & $2.2 \%$ & $2,0 \%$ & $3.4 \%$ & $4.3 \%$ & $4.3 \%$ & $78,0 \%$ \\
& $100 \%$ & $100 \%$ & $100 \%$ & $100 \%$ & $100 \%$ & $100 \%$ & $100 \%$ \\
\hline
\end{tabular}

Nota: Elaboración propia.

Al consultar sobre cuáles serían los principales conocimientos y principales habilidades que debe tener un profesor para un adecuado ejercicio de su profesión un $44.2 \%$ menciona a la Psicología Educativa, lo que se puede ver en la tabla 9 como primera preferencia en torno al conocimiento y un $32.2 \%$ cree en primera preferencia que es escuchar, lo que se puede observar en la tabla 10 como una habilidad que debiera poseer el profesor para un adecuado ejercicio de su profesión. 
Tabla 10.

Jerarquización de Conceptos con respecto a las habilidades para un adecuado ejercicio de la profesión

\begin{tabular}{lrrrrrrr}
\hline & $1^{\circ}$ & $2^{\circ}$ & \multicolumn{1}{c}{$3^{\circ}$} & $4^{\circ}$ & \multicolumn{1}{c}{$5^{\circ}$} & $6^{\circ}$ & $7^{\circ}$ \\
\hline Escuchar & $32.2 \%$ & $29.1 \%$ & $23,0 \%$ & $10.9 \%$ & $3.4 \%$ & $1.1 \%$ & $0.2 \%$ \\
Empatía & $23.4 \%$ & $25.2 \%$ & $18.8 \%$ & $21.6 \%$ & $8.3 \%$ & $2.2 \%$ & $0.5 \%$ \\
Motivar & $24.5 \%$ & $21.9 \%$ & $26.4 \%$ & $18.7 \%$ & $6.5 \%$ & $1.5 \%$ & $0.5 \%$ \\
Hablar & $9.4 \%$ & $17.8 \%$ & $23.2 \%$ & $34,0 \%$ & $13.1 \%$ & $2.2 \%$ & $0.2 \%$ \\
Escribir & $2.6 \%$ & $1.8 \%$ & $3.3 \%$ & $7,0 \%$ & $51.4 \%$ & $29.2 \%$ & $4.7 \%$ \\
Juzgar & $1,0 \%$ & $1.7 \%$ & $1.7 \%$ & $3.4 \%$ & $11.9 \%$ & $50.5 \%$ & $29.8 \%$ \\
Otro. ¿Cuál? & $7.0 \%$ & $2.4 \%$ & $3.6 \%$ & $4.3 \%$ & $5.3 \%$ & $13.3 \%$ & $64.1 \%$ \\
& $100 \%$ & $100 \%$ & $100 \%$ & $100 \%$ & $100 \%$ & $100 \%$ & $100 \%$ \\
\hline
\end{tabular}

Nota: Elaboración propia.

De acuerdo a la jerarquización de conceptos asociados al ejercicio docente realizada por Macrozona, género, tipo de establecimiento de procedencia de los estudiantes se puede observar y determinar que el comportamiento en primera preferencia por cada una de ellas es similar que en términos globales, los porcentajes varían solo pequeñas cantidades. Sin embargo, a excepción de la Macrozona Sur, en la pregunta asociada a cuáles son las principales habilidades que debe tener un profesor para un adecuado ejercicio de su profesión el 30.7\% escogió en primera referencia Motivar y no Escuchar como el resto de las Macrozonas, los resultados por Macrozona, género y tipos de establecimiento pueden observarse en la tabla 11.

Tabla 11.

Resumen de la jerarquización de conceptos por Macrozona, género y tipo de establecimiento

\begin{tabular}{|c|c|c|c|}
\hline & & $\begin{array}{c}\text { Los principales } \\
\text { conocimientos que } \\
\text { debe saber un profesor } \\
\text { para un adecuado } \\
\text { ejercicio de su } \\
\text { profesión son. } \\
\text { Psicología Educativa }\end{array}$ & $\begin{array}{l}\text { Las principales } \\
\text { habilidades que } \\
\text { debe tener un } \\
\text { profesor para un } \\
\text { adecuado ejercicio } \\
\text { de su profesión son. } \\
\text { Escuchar }\end{array}$ \\
\hline \multirow[t]{7}{*}{ Macrozona } & Macrozona Norte & $46.8 \%$ & $33.9 \%$ \\
\hline & Macrozona Centro & $43.4 \%$ & $32.0 \%$ \\
\hline & Norte & & \\
\hline & Macrozona Centro & $43.1 \%$ & $31.0 \%$ \\
\hline & Sur & & \\
\hline & Macrozona Sur & $41.7 \%$ & $28.2 \% *$ \\
\hline & Macrozona Austral & $48.1 \%$ & $42.0 \%$ \\
\hline \multirow[t]{2}{*}{ Género } & Hombre & $41.2 \%$ & $31.7 \%$ \\
\hline & Mujer & $46.5 \%$ & $32.6 \%$ \\
\hline Tipo de & Público & $42.2 \%$ & $32.7 \%$ \\
\hline \multirow[t]{2}{*}{ Establecimiento } & Subvencionado & $45.6 \%$ & $30.9 \%$ \\
\hline & Pagado & $45.9 \%$ & $47.5 \%$ \\
\hline Global Estudio & & $44.2 \%$ & $32.2 \%$ \\
\hline
\end{tabular}

Nota: Elaboración propia. 


\section{Discusión}

Se puede comprender en cuanto a las competencias docentes (Pavié, 2011) propias del profesor en cuanto profesional socialmente reconocido, y que se consideran factores positivos para realizar un adecuado ejercicio profesional de la enseñanza. Es esta línea resaltan conceptos-ideas como: dominio de conocimientos, saberes (para enseñar), valores, motivación, entre otros. Particularmente, los estudiantes que inician su formación inicial señalan en las respuestas abiertas, que el profesor - para un efectivo ejercicio de la profesión- debe tener conocimientos, habilidades o herramientas para enseñar para que cumpla su función (que es enseñar) adecuadamente.

Entre los argumentos esgrimidos se encuentran expresiones del tipo: "tener competencias para enseñar", "adecuada formación en capacidades para la enseñanza y conocimientos de las personas, "que entienden y saben de diversidad e inclusión" o "saber de metodologías motivantes según el tema que tratará en la clase". Dichas expresiones reafirman la idea de que para ejercer la profesión se debe tener habilidades o conocimientos. Esto implicaría, por un lado, tener altas capacidades cognitivas y de personalidad para el desarrollo de la profesión docente y, por otro, disponer del dominio de determinados saberes. En relación a esto último, el saber que aparece jerarquizado como primera prioridad es Psicología Educativa (44,2\%), con argumentos del tipo "hay que entender cómo se enseña a los estudiantes", "si no sabemos de sus problemas no sabemos cómo trabajar" o "hay que saber de los problemas de aprendizaje", "la diversidad es como pensamos y entendemos" (respuestas abiertas). El otro saber es Sociología de la Educación (jerarquizado como segunda prioridad con un 28,9\%), lo que se respalda en expresiones del tipo "trabajo en grupo", "como colaborar con otros" y "cómo nos organizamos para aprender entre nosotros", cuyos segmentos fueron documentados en las respuestas abiertas. En síntesis:

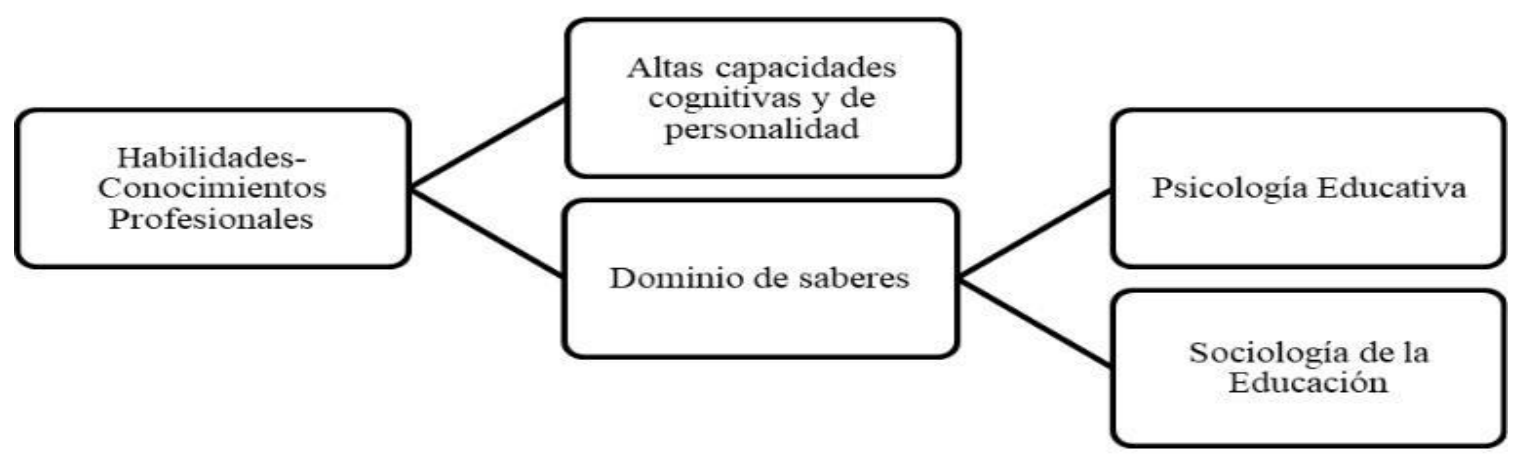

Figura 2. Representaciones de la Profesión Docente como Habilidades-Conocimientos Profesionales

En cuanto a las condiciones del ejercicio profesional docente para la enseñanza; específicamente, los conceptos-ideas que contribuyen a este aspecto hacen referencia a la finalidad o función (social) de enseñar y las condiciones sociales y materiales del ejercicio de la profesión docente. En estas líneas surgen conceptos centrales como estudiantes (los que deben aprender), realidad y justicia. En concreto, se desprende que los estudiantes que inician su formación inicial señalan que la profesión docente se relaciona con enseñar a los estudiantes. Es decir, existe una relación directa entre enseñar para el aprendizaje de los estudiantes. Así, se parte del supuesto que cuando se codifica la noción de "estudiantes", de manera explícita e implícita se está aludiendo a la idea de que son ellos la meta de acto de enseñar, es decir que aprendan lo que se enseña. Lo anterior se traduce socialmente en un propósito: se busca que los alumnos aprendan. Así, y por lo planteado hasta aquí, queda latente el requerimiento de seguir explorando con este mismo nivel de profundidad las demás dimensiones propuestas en el instrumento base, ampliando 
la cobertura de dicho trabajo con más las Universidades que ofrecen programas de Formación Inicial Docente (FID) en una nueva investigación.

\section{Conclusiones}

En términos generales, el presente estudio ha tenido como principal propósito identificar, describir y comparar las representaciones sobre la profesión docente, que han elaborado los estudiantes que ingresan a estudiar carreras de Pedagogías, específicamente en el contexto del ejercicio profesional docente de siete universidades regionales estatales del país.

En coherencia con el marco teórico de Moscovici (1979), quien señala que la representación se construye en torno a tres dimensiones (la información, el campo representado y la actitud), el presente estudio trata de indagar sobre el conocimiento no especializado y de sentido común que han construido los futuros docentes al comienzo de su Formación Inicial Docente (FID). Considerando los objetivos de la indagación, se puso especial atención en trabajar en dos de las dimensiones: información y valoración (actitud) en torno a la profesión docente, bajo la premisa que estas ideas se han construido de manera natural, y se encontrarían ancladas actitudinal y cognitivamente antes de comenzar a adquirir y desarrollar sus saberes y/o conocimientos especializados o disciplinares.

En este contexto planteado, disponer de esta información sobre las representaciones resulta de especial interés, dado que es el punto de entrada para que las instituciones formadoras puedan construir y/o re-construir conocimientos (saberes) especializados de la profesión, bajo el supuesto que ello permitirá orientar la formación de sus egresados en un futuro desempeño profesional más pertinente a las necesidades de los saberes especializados, a los nuevos contextos siempre cambiantes y a las demandas de las políticas actuales sobre la profesión docente y el ejercicio de dicha profesión.

Se refrenda primero en este estudio, un dato que es histórico ya que de la muestra total un $61 \%$ corresponde a mujeres, por lo que la proyección hacia el ejercicio profesional docente es que seguirá teniendo un fuerte sesgo femenino. Junto con lo anterior, de esta población total encuestada un $41 \%$ declara que tiene algún familiar que haya ejercido como docente y allí puede observarse una posible influencia en la toma de decisiones al elegir la carrera que, en el caso de este estudio, un $81 \%$ postuló en primera instancia a estudiar una Pedagogía. También se considera importante tomar en cuenta que más de la mitad de los postulantes a una carrera pedagógica proviene de un establecimiento municipal, que en este caso corresponde a un $56 \%$ de la muestra y que un $25 \%$ de esta se declara perteneciente a un pueblo originario.

Al analizar los resultados obtenidos entre las Universidades en estudio se constata también que la tendencia de respuesta en las universidades tiende a ser similares - con algunas excepciones - en la dimensión del ejercicio profesional. Lo anterior se establece en cuanto que se observa que las universidades declaran tener una percepción positiva (más del 90\%). De los 10 ítems que componen la dimensión de ejercicio profesional docente, 8 tienen más del $90 \%$ de percepción positiva. De las otras dos restantes su valoración positiva llega a un 76,9\% en el ítem 27 , sobre si el profesor representa la autoridad de la sociedad en una sala de clases, y un 56,9\% (ítem 31) sobre si las calificaciones son una de las principales funciones del profesor. Tomando en cuenta estos datos, hombres y mujeres responden de manera muy similar en esta dimensión sin haber diferencias significativas.

En lo relacionado a la jerarquización de conceptos, al consultar sobre cuáles serían los principales conocimientos y principales habilidades que debe tener un profesor para un adecuado ejercicio de su profesión un 44,2\% menciona a la Psicología Educativa (ver tabla 8) como primera preferencia en torno al conocimiento y un $32,2 \%$ cree en primera preferencia que es escuchar (ver tabla 9) es una habilidad que debiera poseer el profesor para un adecuado ejercicio de su profesión. De acuerdo a esta misma jerarquización de conceptos relacionados al ejercicio profesional 
docente realizada por Macrozona, género, tipo de establecimiento de procedencia de los estudiantes se puede observar y determinar que el comportamiento en primera preferencia por cada una de ellas es similar que, en términos globales, los porcentajes varían solo en pequeñas cantidades. Sin embargo, a excepción de la Macrozona Sur, en la pregunta asociada a cuáles son las principales habilidades que debe tener un profesor para un adecuado ejercicio de su profesión el 30,7\% escogió en primera referencia Motivar y no Escuchar como el resto de las Macrozonas.

En cuanto a lo señalado en este apartado, se considera relevante insistir que las representaciones sociales (RS) de la dimensión denominada ejercicio profesional docente abordada en este estudio son compartidas en general independiente de la carrera que se ha elegido estudiar. Por esto, es importante consignar que, por los datos mostrados, la noción del ejercicio profesional comienza con bastante anterioridad a que el sujeto adquiera de manera formal y sistemática la formación ad hoc para dicho ejercicio profesional. Por lo anterior, creemos importante tomar en consideración el diseño de un Plan de acompañamiento y/o mejora que aborde en conjunto, para estas carreras pedagógicas, los resultados obtenidos a partir de este diagnóstico presentado. Así, desde que ingresa a un programa formativo en Pedagogía, comienza un proceso de "enculturación escolar" (Rosso \& Alcalá, 2016) en base al cual el futuro profesor re-construye concepciones, representaciones y creencias en lo relativo a lo que significa ser un buen profesor y, además, aprende teorías y constructos sobre didáctica y la especialidad seleccionada para la toma de decisiones de qué y cómo enseñar en una sala de clases.

Asimismo, en base a lo anteriormente planteado, se hace necesario seguir profundizando en investigaciones que asocien lo que proporciona la Formación Inicial Docente (FID) como oportunidad para reflexionar y aprender y, en función de esto, establecer un nexo coherente y articulado con las demandas que se plantean hoy del ejercicio profesional docente y las políticas educativas ad hoc de la FID. También resultaría pertinente retrasar el aumento de la selectividad en universidades regionales y fortalecer los diagnósticos iniciales a estudiantes y analizar si el instrumento actual de la Evaluación Nacional Diagnóstica es pertinente y si entrega información relevante para la retroalimentación y la toma de decisiones de las Instituciones de Educación Superior que forman profesores en el país (Medina, 2018; Cabezas et al., 2019).

Finalmente, cabe aquí un espacio para conminar al mundo académico de la FID a repensar el trabajo que realizan con los futuros profesores en cuanto al rol y/o función que estos desempeñan en el proceso formativo de estos últimos. Lo anterior basado en que junto con el apoyo teórico y disciplinar proporcionado en un programa de Pedagogía puntual, el académico y el futuro docente deben diseñar en conjunto experiencias de aprendizaje que le faculten a este profesor en formación a mejorar sus competencias profesionales docentes, aprender y aprender a enseñar a través de un conocimiento adquirido y transformado para la acción práctica de este nuevo profesional de la educación (Pavié, 2020). Y, por último, que en los procesos de acreditación que establece la Comisión Nacional de Acreditación (CNA) a partir de sus criterios y orientaciones, se garantice la coherencia y la pertinencia en aspectos tales como:

1) Los procesos formativos, el perfil de egreso y los estándares pedagógicos y disciplinarios planteados por el Ministerio de Educación (MINEDUC).

2) Convenios de colaboración formales con centros educativos para la realización de prácticas tempranas y profesionales.

3) Los procesos de acreditación vigilados por la CNA aseguren el monitoreo efectivo de los programas que forman profesores tanto a nivel de planes de mejora dentro del mismos programas, como también lo relacionado con el seguimiento de los egresados de las respectivas carreras pedagógicas. 


\section{Referencias}

Abric, C. (2001). Metodología de recolección de las representaciones sociales, en J.C. Abric, Prácticas sociales y representaciones. Filosofía y cultura contemporánea $\mathrm{N}^{\circ} 16$. México: Ediciones Coyoacán.

Álvarez, B., \& Ruiz-Casares, M. (eds.) (1997). Evaluación y reforma educativa; opciones de política. Santiago de Chile: PREAL.

Araya, S. (2002). Las representaciones sociales: eje teórico para su discusión. Cuadernos de Ciencias Sociales 127. Costa Rica: Facultad Latinoamérica de Ciencias Sociales FLACSO.

Ávalos, B. (2001). Docencia profesional y su ejercicio. La profesión de la docencia, en Revista Calidad de la Educación, 15, 1-18.

Ávalos, B. (2014). La formación inicial docente en Chile: tensiones entre políticas de apoyo y control. Estudios Pedagógicos, 40, número especial 1, 11-28.

Banchs, M. (1986). Concepto de representaciones sociales: análisis comparativo. Revista Costarricense de Psicología, 8-9, 27-40. Recuperado en http://rcps-cr.org/wpcontent/uploads/2016/05/1986.pdf

Barber, M., \& Mourshed, M. (2008). Cómo hicieron los sistemas educativos con mejor desempeño del mundo para alcanzar sus objetivos. $\mathrm{N}^{\circ}$ 41. PREAL, Santiago: CINDE. Recuperado en http://www.oei.es/pdfs/documento_preal41.pdf

Berger, P., \& Luckmann, T. (1993). La construcción social de la realidad. Buenos Aires: Amorrortu. (Trabajo original publicado en 1967).

Bristzman, D. P. (2003). Practice Makes Practice: a Critical Study of Learning to Teach, Revised Edition. NY: State University of New York Press.

Cabezas, V., Medina, L., Müller, M. \& Figueroa, C. (2019). Desafíos y tensiones entre las nuevas plíticas educativas y los prgramas de formación incial de profesores en Chile, en Temas de Agenda Pública. Centro de Políticas Públicas UC, año 14 (116), 1-28.

Caine, V., \& Steeves, P. (2009). Imagining and playfulness in narrative inquiry. International Journal of Education \& the Arts, 10(25), 1-15.

Comisión Nacional de Acreditación (CNA), (2018). Carreras de pedagogía: análisis de fortalezas y debilidades en el escenario actual. Santiago: Serie de Estudios.

Contreras, J. (1985). ¿El pensamiento o conocimiento del profesor? Una crítica a los postulados de las investigaciones sobre el pensamiento del profesor y sus implicaciones para la formación del profesoraso. Revista de Educación 277, 5-28.

Correa, E. (2011). La práctica docente: una oportunidad de desarrollo profesional. Perspectiva Educacional, Formación de Profesores, 50(2), 77-95.

Craig, C.J. (2016). "Structure of Teacher Education", en Loughran, J. \& Hamilton, M.L. (Eds.), International Handbook of Teacher Education. (2016). Singapore: Springer, 69-135.

Domínguez, F. (2001). Teoría de las representaciones. Apuntes. Nómadas. Revista Crítica de Ciencias Sociales y Jurídicas (3), 1-16.

Durkheim, E. (2001). Las reglas del método sociológico. Madrid: Akal. (Trabajo original publicado en 1895).

Durkheim, E. (1987). La división del trabajo social. Madrid: Akal (Trabajo original publicado en 1987)

Eisner, E. (1998). El ojo ilustrado: indagación cualitativa y mejora de la práctica educativa. Madrid: Ed. Paidós.

García, L., Domínguez, R., \& Del Toro Valencia, M. (2018). La profesionalización docente, responsabilidad ineludible en Educación Media Superior. Debates en Evaluación y Currículum/Congreso Internacional de Educación Currículum 2017. Recuperado en http://posgradoeducacionuatx.org/pdf2017/A006.pdf

Gimeno Sacristán, J. (1982). La formación del profesorado en la universidad Las escuelas universitarias de F. del P. de E.G.B. Revista de Educación, 269, 77-99.

Goetz, J., \& Lecompte, M. (1988). Etnografía y diseño cualitativo en investigación educativa. Madrid: Morata. 
Gorgas, J., Cardiel, N., \& Zamorano, J. (2011). Estadística básica para estudiantes de Ciencias. Madrid: Universidad Complutense de Madrid.

Hargreaves, A., \& Fullan, M. (2014). Capital profesional. Madrid: Morata.

Hirmas, C. (2014). Tensiones y desafíos para pensar el cambio en la formación práctica de futuros profesores. Estudios Pedagógicos, 40, número especial, 127-143.

Jerez, O., Orsini, C., \& Hasbún, B. (2016). Atributos de una docencia de calidad en la educación superior: una revisión sistemática. Revista Estudios Pedagógicos, 48(3), 483-506.

Jarauta, B. (2017). La construcción de la identidad profesional del maestro de primaria durante su formación inicial. El caso de la universidad de Barcelona. Profesorado, Revista de Currículum y Formación de Profesorado, 21(1), 103-122.

Jodelet, D. (1986). La representación social: fenómenos, conceptos y teoría. En: Moscovici, S. Psicología social II. Pensamiento y vida social. Psicología social y problemas sociales. Barcelona: Paidós; 1986, 469-494. Recuperado en https://sociopsicologia.files.wordpress.com/2010/05/rsociales-djodelet.pdf

Kaplan, C. (1997). La inteligencia escolarizada. Buenos Aires: Miño y Dávila.

Latorre, A., Del Rincón, D., \& Arnal, J. (1997). Bases Metodológicas de la Investigación Educativa. Barcelona: Ed. Hurtado.

Latorre, M. (2006). Nuevas miradas, viejos problemas: Las relaciones entre formación inicial y ejercicio profesional docente. En Foro Educacional 10, 41-63. Recuperado en https://dialnet.unirioja.es/servlet/articulo?codigo $=2292721$

Marcelo, C. (2016). Estado del arte internacional de los modelos de Formación Inicial Docente: FID. Sevilla: CM UPA 1556.

Medina, L., (2018). A casi dos años de la promulgación de la Ley 20.903: avances, tensiones y desafíos del sistema de desarrollo profesional docente. Ideas en Educación II. Definiciones en Tiempos De Cambio.

Meo, A. (2010). Consentimiento informado, anonimato y confidencialidad en investigación social. La experiencia internacional y el caso de la Sociología en Argentina. Aposta. Revista de Ciencias Sociales, 44, 1-30. Recuperado en http://www.apostadigital.com/revistav3/hemeroteca/aines.pdf

Ministerio de Educación de Chile (MINEDUC). (2006). Actualizada 29 mayo 2018). Ley $\mathrm{N}^{\circ}$ 20.129 "establece un sistema nacional de aseguramiento de la calidad de la educación". Recuperado de https://www.leychile.cl/Navegar?idNorma=255323

Montero, L. (2001). La construcción del conocimiento profesional docente. Rosario: Homo Sapiens Ediciones.

Mora, M. (2002). La teoría de las representaciones sociales de Serge Moscovici. Athenea Digital, 2 , $1-25$.

Recuperado

de http://www.raco.cat/index.php/Athenea/article/viewFile/34106/33945

Moral, C. (2010). Didáctica. Teoría y práctica de la enseñanza. Madrid: Akal.

Moscovici, S. (1998). The history and actuality of social representations. En Flick, U. (Ed.): The psichology of the social. Cambridge: Cambridge U.P. (pp. 209-247).

Moscovici, S. (1979). El psicoanálisis, su imagen y su público. Buenos Aires: ANESA-HUEMUL

Muñoz, J., González, M., \& Rodríguez, M. (2018). Los Contenidos de la formación continuada del profesorado: ¿qué docentes se están formando? Educación XX1. 21(1), 157-180. Recuperado de http://www.redalyc.org/pdf/706/70653466008.pdf

Muñoz J., López, M., \& Alonso, J. (2017). Aprendizaje docente y desarrollo profesional del profesorado. Profesorado. Revista de Currículum y Formación del Profesorado, 21(3), 83-102.

Neiman, G., \& Quaranta, G. (2006). Los estudios de caso en la investigación sociológica. En De Gialdino, Vasilachis (comp.), Estrategias de investigación cualitativa. Buenos Aires: Gedisa.

Núñez, I. (2001). Valoración de la profesión docente en Chile. Contextos: Estudios de Humanidades y Ciencias Sociales, 7, 63-69. Recuperado en http://revistas.umce.cl/index.php/contextos/article/view/799/777 
Pavié, A. (2011). Formación docente: hacia una definición del concepto de competencia profesional docente. REIFOP, 14(1), 67-80.

Pavié, A. (2020). Lengua y literatura: aspectos y perspectivas para la formación inicial docente en el contexto del Chile actual. Revista ALPHA, 50. (en prensa).

Pozo, J.L. (2009). Adquirir una concepción compleja del conocimiento: creencias epistemológicas y concepciones del aprendizaje. En Pozo, J. L. y Pérez, M. P. (Eds.). Psicología del estudiante universitario: La formación en competencias. Madrid: Morata.

Pozo, J.L. (2014). Psicología del aprendizaje humano. Adquisición de conocimiento y cambio personal. Madrid: Morata.

Reimers, F. (2000). Educación, desigualdad y opciones de política en América Latina. Revista Iberoamericana de educación, 23, 21-50.

Rosso, I., \& Alcalá, M. (2016). La formación docente y el ejercicio profesional de los noveles de profesores en Historia. Revista del Instituto de Investigaciones en Educación, 7(9), 4970.

Ruffinelli, A. (2014). ¿Qué aprenden los docentes en su primer año de ejercicio profesional?: representaciones de los propios docentes principiantes. Pensamiento Educativo. Revista de Investigación Educacional Latinoamericana, 51(2), 56-74.

Ruffinelli, A., Cisternas, T., \& Córdoba, C. (2017). Iniciarse en la docencia. Relatos de once experiencias. Santiago: Ediciones Universidad Alberto Hurtado.

Russell, T. (2014). La práctica en la formación de profesores: tensiones y posibilidades en la experiencia de aprender a enseñar. Estudios Pedagógicos (Valdivia), 40(número especial), 223-238. doi: https://dx.doi.org/10.4067/S0718-07052014000200013

Sánchez, C. (2013). Estructuras de la Formación Inicial Docente. Perfiles Educativos, 35(142), $128-148$.

Sandoval, M. (2009) Educación de calidad y desempeño docente. Ánfora, 16(2), 24-36. Recuperado de http://www.redalyc.org/articulo.oa?id=357834259001

Taylor, S., \& Bogdan, R. (1990). Introducción a los métodos cualitativos de investigación. Madrid: Ed. Paidós.

Vaillant, D. (2005). Formación de docentes en América Latina. Re-inventando el modelo tradicional. Barcelona: Ed. Octaedro.

Vaillant, D. (2014). Análisis y reflexiones para pensar el desarrollo profesional docente continuo. Educar, 30, 55-66.

Vélaz de Medrano, C. \& Vaillant, D. (2009). Aprendizaje y desarrollo profesional docente Madrid: OEI - $\quad$ Fundación Santillana. Recuperado en https://www.oei.es/historico/publicaciones/detalle_publicacion.php?id=2

Nota: Este artículo constituye un avance de los resultados a partir del proyecto de investigación titulado "Representaciones sobre la Profesión Docente que poseen estudiantes que ingresan a la Formación Inicial Docente en universidades del Estado", FONIDE (Fondo de Investigación y Desarrollo en Educación) código FON 181800090, convocatoria nº 12, 2018. 